\title{
STRATEGI PEMBERDAYAAN WANITA NELAYAN DALAM PENINGKATAN EKONOMI KELUARGA DI GAMPONG LANGKAK KECAMATAN KUALA PESISIR KABUPATEN NAGAN RAYA
}

\author{
Strategy Of Fishermen Women Empowerment In Increasing Famili Economy In Langkak \\ Village Kuala Pesisir Districts Nagan Raya District
}

\author{
Cut Irma Aflandari ${ }^{1}$, Sofyan ${ }^{1}$, Edy Marsudi ${ }^{*}$ * \\ ${ }^{1}$ Program Studi Agribinis, Fakultas Pertanian, Universitas Syiah Kuala
}

\begin{abstract}
Abstrak. peran pemberdayaan wanita nelayan sangat di perlukan untuk membantu ekonomi keluarga. Wanita-wanita di daerah pesisir bisa menjadi motor penggerak kegiatan ekonomi produktif fungsinya dari ibu rumah tangga biasa menjadi pencari nafkah seperti melakukan kegiatan pengolahan ikan dan lain sebagainya. Penelitian ini bertujuan untuk mengetahui bentuk kegiatan keluarga nelayan di Gampong Langkak Kecamatan Kuala Pesisir Kabupaten Nagan Raya dalam meningkatkan ekonomi keluarga, dan rencana strategi perempuan nelayan dalam meningkatkan ekonomi keluarga di Gampong Langkak Kecamatan Kuala Pesisir Kabupaten Nagan Raya. Metode yang digunakan dalam penelitian ini adalah pendekatan kualitatif dan analisis SWOT. Hasil dalam penelitian ini didapat strategi wo sebagai rencana strategi pemberdayaan wanita nelayan. Srategi wo yaitu memanfaatkan peluang yang ada dengan cara meminimalkan kelemahan yang ada. Adapun bentuk kegiatan keluarga adalah bertani, jemur udang sabu dan buruh pabrik.
\end{abstract}

Kata kunci: pemberdayaan, keluarga , nelayan.

Abstract. the role of empowering women fishermen is very much needed to help the family economy. Women in coastal areas can be the driving force of productive economic activities whose function is from ordinary housewives to being breadwinners such as fish processing activities and so on. This study aims to determine the form of fishermen's family activities in Gampong Langkak, Kuala Pesisir Subdistrict, Nagan Raya District in improving the family's economy, and the strategy of women fishermen in improving the family's economy in Ganggong Langkak, Kuala Pesisir District, Nagan Raya District. The method used in this study is a qualitative approach and SWOT analysis. The results in this study obtained the WO strategy as a plan to empower women fishermen strategies. The strategy is to take advantage of existing opportunities by minimizing existing weaknesses. The form of family activities is farming, drying shabu shrimp and factory workers.

Keywords : empowerment, family, fishermen.

\section{PENDAHULUAN}

Nagan Raya merupakan salah satu Kabupaten baru, pecahan dari Kabupaten Aceh Barat. Nagan Raya memiliki panjang garis pantai lebih kurang 74,4 Km. masyarakat dikawasan pesisir ini sebagian besar berprofesi sebagai nelayan yang di peroleh secara turun temurun dari nenek moyang mereka. Resiko dari usaha yang tinggi yang menyebabkan masyarakat nelayan hidup dalam suasana alam yang keras yang selalu diliputi ketidakpastian disebabkan oleh cuaca yang tidak menentu sehingga mempengaruhi usahanya.

Dalam hal ini peran pemberdayaan wanita nelayan sangat di perlukan untuk membantu ekonomi keluarga. Wanita-wanita di daerah pesisir bisa menjadi motor penggerak kegiatan ekonomi produktif fungsinya dari ibu rumah tangga biasa menjadi pencari nafkah seperti melakukan kegiatan pengolahan ikan dan lain sebagainya. 
Pengantisipasian hal tersebut berbagai cara dilakukan oleh keluarga nelayan dalam mengatasi kesulitan ekonominya. Namun, kesulitan nelayan dengan kondisi ekonomi dan lingkungan yang di tempatinya tentunya memiliki perbedaan strategi dalam meningkatkan ekonomi keluarga seperti halnya nelayan di Gampong Langkak Kecamatan Kuala Pesisir Kabupaten Nagan Raya yang mayoritas penduduknya adalah bekerja sebagai nelayan tradisional.

Para keluarga Gampong Langkak memiliki strategi berbeda yang dilakukan yakni, dengan adanya lapangan kerja yang sudah di bangun oleh pemerintah setempat akan lebih memudahkan anggota keluarga untuk memenuhi kebutuhan ekonomi keluarga. Strategi tersebut mereka lakukan karena ada faktor pendukung berupa lahan untuk bertani, dan lokasi penjemuran dengan memanfaatkan lokasi pelabuhan perdaratan ikan (PPI) dan tempat pelelangan ikan (TPI) sehingga para istri nelayan bisa dengan leluasa menggunakan tempat tersebut tanpa ada yang menghalangi. Berdasarkan latar belakang diatas, maka masalah dapat dirumuskan sebagai berikut: Apa bentuk kegiatan keluarga nelayan di Gampong Langkak Kecamatan Kuala Pesisir Kabupaten Nagan Raya dalam meningkatkan ekonomi keluarga ? Apakah rencana strategi perempuan nelayan dalam meningkatkan ekonomi keluarga di Gampong Langkak Kecamatan Kuala Pesisir Kabupaten Nagan Raya? Adapun tujuan dari penelitian ini adalah Mengidentifikasi bentuk-bentuk kegiatan keluarganelayan di Gampong Langkak Kecamatan Kuala Pesisir Kabupaten Nagan Raya dalam meningkatkan ekonomi keluarga dan Mengetahuirencana strategi perempuan nelayan dalampeningkatkan ekonomi keluarga di Gampong Langkak Kecamatan Kuala Pesisir Kabupaten Nagan Raya.

\section{Lokasi dan Waktu Penelitian}

\section{METODE PENELITIAN}

Penelitian ini dilakukan di Gampong Langkak Kecamatan Kuala Pesisi Kabupaten Nagan Raya. Penentuan lokasi penelitian dilakukan secara sengaja dengan pertimbangan bahwa rata-rata penduduknya bermata pencaharian sebagai nelayan. Adapun waktu penelitian Berlangsung dari bulan september 2016 hingga selesai

\section{Objek dan Ruang Lingkup Penelitian}

Objek kunci dalam penelitian ini adalah anggota keluarga nelayan yang ikut bekerja untuk memenuhi kebutuhan yang terdiri dari ayah, ibu dan anak.

\section{Sumber dan Metode Pengumpulan Data}

Tipe penelitian dalam penelitian ini adalah deskriptif. Pendekatan yang digunakan dalam penelitian ini adalah pendekatan kualitatif. Pendekatan kualitatif digunakan karena penelitian ini bertujuan untuk menjelaskan lebih dalam mengenai strategi keluarga yang mungkin dilakukan dalam meningkatkan ekonomi keluarga di Gampong Langkak Kecamatan Kuala Pesisir Kabupaten Nagan Raya. Pengumpulan data dalam penelitian terdiri data primer dan sekunder.

\section{Model Analisis}

Menjawab masalah 1 yaitu untuk mengetahui bentuk kegiatan keluarga nelayan di Gampong Langkak Kecamatan Kuala Pesisir Kabupaten Nagan Raya dalam peningkatkan ekonomi keluarga dilakukan dengan analisis deskriptif yang mengacu pada hasil wawancara dengan keluarga nelayan.

Menjawab masalah 2 yaitu untuk mengetahui rencana strategi pemberdayaan wanita nelayan dalam peningkatkan ekonomi keluarga di Gampong Langkak Kecamatan Kuala 
Pesisir Kabupaten Nagan Raya dapat dilakukan dengan menggunakan metode analisis SWOT.

Tabel 1. Format analisis SWOT untuk faktor Internal dan Eksternal

\begin{tabular}{l|l|l|l}
\hline \multicolumn{1}{c|}{ Uraian } & Bobot & Rating & Bobot x Rating \\
\hline I. KEKUATAN & & & \\
1. & & & \\
2. & & & \\
\hline $\begin{array}{l}\text { II. KELEMAHAN } \\
1 .\end{array}$ & & & \\
2. & & & \\
\hline III. PELUANG & & \\
1. & & \\
2. & & & \\
\hline IV. ANCAMAN & & & \\
1. & & & \\
2. & & & \\
\hline
\end{tabular}

\section{Total}

Irham, 2013

Matriks Analisis SWOT

\begin{tabular}{|c|c|c|}
\hline IFAS & $\begin{array}{c}\text { Strengths (S) } \\
\text { Daftar semua kekuatan } \\
\text { yang dimiliki }\end{array}$ & $\begin{array}{c}\text { Weaknesses }(\mathrm{W}) \\
\text { Daftar semua kelemahan } \\
\text { yang dimiliki }\end{array}$ \\
\hline Opportunities $(\mathrm{O})$ & Strategi SO & Strategi WO \\
\hline $\begin{array}{l}\text { Daftar semua } \\
\text { peluang yang dapat } \\
\text { diidentifikasi. }\end{array}$ & $\begin{array}{l}\text { Gunakan semua } \\
\text { kekuatan yang dimiliki } \\
\text { untuk memanfaatkan } \\
\text { peluang yang ada. }\end{array}$ & $\begin{array}{l}\text { Atasi semua kelemahan } \\
\text { dengan memanfaatkan } \\
\text { semua peluang yang ada. }\end{array}$ \\
\hline Threats $(\mathrm{T})$ & Strategi ST & Strategi WT \\
\hline $\begin{array}{l}\text { Daftar semua } \\
\text { ancaman yang } \\
\text { dapat diidentifikasi. }\end{array}$ & $\begin{array}{l}\text { Gunakan semua } \\
\text { kekuatan untuk } \\
\text { menghindari dari semua } \\
\text { ancaman. }\end{array}$ & $\begin{array}{l}\text { Tekan semua kelemahan } \\
\text { dan cegah semua } \\
\text { ancaman. }\end{array}$ \\
\hline
\end{tabular}

Irham, 2013

\section{HASIL PENELITIAN DAN PEMBAHASAN}

Jenis pekerjaan yang dilakukan sesuai dengan keahlian yang sudah dimiliki oleh setiap anggota keluarga untuk memudahkan melakukan kegiatan tersebut. Berbagai upaya ataupun strategi yang dilakukan dalam meningkatkan ekonomi keluarga di 
GampongLangkak yang jadikan sebagai pilihan dari mata pencaharian lainnya diantaranya bertani, usaha jemur udang sabu dan buruh pabrik.

Tabel 2. Besarnya Frekuensi Bentuk Kegiatan Keluarga Nelayan

\begin{tabular}{rlcc}
\hline No & \multicolumn{1}{c}{ Bentuk Kegiatan Keluarga } & Jumlah & Persentase (\%) \\
\hline 1 & Bertani & 5 & 30 \\
2 & Usaha jemur udang sabu & 10 & 55 \\
3 & Buruh pabrik & 3 & 15 \\
& $\quad$ Jumlah & 18 & 100 \\
\hline
\end{tabular}

Sumber: data primer diolah 2016

Dapat diketahui bahwa hasil persentase terbesar berada pada usaha jemur udang sabu, hal ini disebabkan karena kegiatan ini sudah jadi pekerjaan tambahan keluarga nelayan secara turun temurun di Gampong Langkak. Dengan adanya sistim kerja lain selain melaut dapat membantu biaya-biaya yang kurang dalam pekerjaan sebagai pelaut jika kondisi alam sedang tidak baik. Anggota keluarga lain yang bekerja diluar bidang perikanan akan menjadi penopang dalam keluarga disaat keuangan keluarga sedang buruk.

Tabel 3. Analisis Faktor Internal Strategi Pemberdayaan Wanita Nelayan di Gampong Langkak Kecamatan Kuala Pesisir Kabupaten Nagan Raya

\begin{tabular}{|c|c|c|c|}
\hline Faktor-Faktor Internal & Bobot & Rating & $\begin{array}{c}\text { Bobot } \\
\mathbf{x} \\
\text { Rating }\end{array}$ \\
\hline $\begin{array}{l}\text { KEKUATAN } \\
\text { - Istri nelayan memiliki waktu luang didarat lebih banyak. } \\
\text { - Jenis Pekerjaan yang dapat dilakukan oleh wanita } \\
\text { cenderung lebih beragam. } \\
\text { - Wanita nelayan memiliki komitmen yang tinggi dalam } \\
\text { mengatur waktu dan keuangan keluarga } \\
\text { - Adanya kelompok wanita yang bekerja sama sebagai } \\
\text { wadah penjemur udang sabu. } \\
\text { - Anak nelayan memiliki pendidikan yang cukup baik, } \\
\text { yaitu rata-rata pada level Sekolah Menengah Atas }\end{array}$ & $\begin{array}{l}0,13 \\
0,12 \\
0,12 \\
0,08 \\
0,08\end{array}$ & $\begin{array}{l}4 \\
3 \\
3 \\
2 \\
2\end{array}$ & $\begin{array}{c}0,52 \\
0,36 \\
0,36 \\
0,16 \\
0,16\end{array}$ \\
\hline $\begin{array}{l}\text { KELEMAHAN } \\
\text { - Rata-rata pendidikan wanita nelayan adalah tingkat } \\
\text { pendidikan } \\
\text { sekolah dasar dan Sekolah Menengah Pertama. } \\
\text { - Wanita nelayan memiliki keterbatasan keterampilan, saat } \\
\text { ini keterampilan yang dimiliki hanya di bidang produksi } \\
\text { udang sabu, petani, dan buruh pabrik. } \\
\text { - Beban Tanggung jawab wanita nelayan lebih banyak atau } \\
\text { berat, disamping memiliki peran sebagai ibu rumah } \\
\text { tangga, juga memiliki peran ganda yaitu sebagai kepala } \\
\text { rumah tangga ketika suami mereka pergi mealaut. } \\
\text { - Dalam } 1 \text { x } 24 \text { jam wanita nelayan harus membagi waktu } \\
\text { untuk keluarga dan bekerja. }\end{array}$ & $\begin{array}{l}0,13 \\
0,12 \\
0,13 \\
0,11\end{array}$ & $\begin{array}{l}-4 \\
-3\end{array}$ & $\begin{array}{l}-0,52 \\
-0,48 \\
-0,52 \\
-0,33\end{array}$ \\
\hline TOTAL & 1,00 & & $-0,29$ \\
\hline
\end{tabular}

Sumber : Data Primer di olah 2017

Strategi pemberdayaan Wanita Nelayan Dalam Peningkatan Ekonomi Keluarga di Gampong Langkak 
Dilihat dari indikator-indikator faktor internal diatas, skor kondisi kekuatan dan kelemahan dari strategi pemberdayaan wanita nelayan di Gampong Langkak kecamatan Kuala Pesisir Kabupaten Nagan Raya berada pada posisi -0,29 yang artinya kondisi nelayan di Gampong Langkak kecamatan Kuala Pesisir Kabupaten Nagan Raya masih rendah.

\begin{tabular}{|c|c|c|c|}
\hline Faktor-Faktor Eksternal & Bobot & Rating & $\begin{array}{l}\text { Bobot } x \\
\text { Rating }\end{array}$ \\
\hline $\begin{array}{l}\text { PELUANG } \\
\text { - Mendapatkan peluang kerja dengan membuat } \\
\text { bahan makanan yang berbahan dasar udang sabu } \\
\text { - Adanya Potensi diluar non kelautan yang dapat } \\
\text { dimafaatkan sebagai sumber ekonomi, missal } \\
\text { pasar. } \\
\text { - Adanya program pemberdayaan wanita dari } \\
\text { Pemerintah dan Swasta }\end{array}$ & $\begin{array}{l}0,21 \\
0,21\end{array}$ & $\begin{array}{l}4 \\
4\end{array}$ & $\begin{array}{l}0,84 \\
0,84 \\
0,57\end{array}$ \\
\hline $\begin{array}{l}\text { ANCAMAN } \\
\text { - Belum ada wadah penyalur kerajinan industri } \\
\text { rumah tangga } \\
\text { - Adanya saingan antar produk hasil laut dari } \\
\text { daerah lain }\end{array}$ & $\begin{array}{l}0,19 \\
0,20\end{array}$ & $\begin{array}{l}-3 \\
-4\end{array}$ & $\begin{array}{l}-0,57 \\
-0,8\end{array}$ \\
\hline
\end{tabular}

\section{TOTAL}

1,00

$\mathbf{0 , 8 8}$

Sumber: Data primer diolah 2017

Dengan melihat posisi startegis meningkatkan strategi pemberdayaan wanita nelayan di Gampong Langkak kecamatan Kuala Pesisir Kabupaten Nagan Raya berdasarkan evaluasi faktor-faktor internal dan eksternal, maka posisi strategiknya berada pada kuadran 2 yaitu yang mendukung strategi WO. Strategi ini diterapkan berdasarkan pemanfaatan peluang yang ada dengan cara meminimalkan kelemahan yang ada. .

Tabel 4. Hasil Rumusan Analisa Strategi Kaitan Program dan Sasaran.

\begin{tabular}{|c|c|c|}
\hline \multirow{3}{*}{\begin{tabular}{l}
\multicolumn{1}{c}{ Strategi } \\
Strategi WO \\
memanfaat peluang \\
yang ada dengan cara \\
meminimalkan \\
kelemahan.
\end{tabular}} & Program & Sasaran \\
\hline & $\begin{array}{l}\text { 1. Program pemberdayaan } \\
\text { wanita dalam meningkatkan } \\
\text { produksi kerajinan berbahan } \\
\text { dasar udang, seperti: } \\
\text { a. Pelatihan wanita nelayan } \\
\text { dalam pembuatan abon. } \\
\text { b. Pelatihan wanita nelayan } \\
\text { dalam pembuatan kerupuk } \\
\text { udang. } \\
\text { c. Pelatihan wanita nelayan } \\
\text { dalam pembuatan terasi }\end{array}$ & $\begin{array}{l}\text { 1. Sasaran Program } \\
\text { Pemberdayaan keluarga } \\
\text { (wanita dan anak) } \\
\text { a. Untuk meningkatkan nilai } \\
\text { tambah dari produk } \\
\text { perikanan } \\
\text { b. Untuk menambah variasi } \\
\text { dari produk udang sabu hasil } \\
\text { perikanan } \\
\text { c. Untuk meningkatkan } \\
\text { keawetan produk perikanan, } \\
\text { pada saat kondisi tangkapan } \\
\text { ikan berlebih }\end{array}$ \\
\hline & $\begin{array}{l}\text { 2. Program } \\
\text { pemberdayaanwanita } \\
\text { nelayan diluar bidang non } \\
\text { kelautan }\end{array}$ & $\begin{array}{l}\text { 2. Sasaran Program non } \\
\text { kelautan } \\
\text { a. Membuka kedai di pesisir } \\
\text { pantai }\end{array}$ \\
\hline
\end{tabular}




\begin{tabular}{|c|l|c|}
\hline Strategi & \multicolumn{1}{|c|}{ Program } & \multicolumn{2}{c|}{ Sasaran } \\
\hline & a. Pelatihan Kewirausahaan & b. Wanita nelayan dapat \\
& b. Pelatihan industri rumahan, \\
& seperti pelatihan membuat \\
kue basah & dijual di pasar yang dapat
\end{tabular}

Sumber: data primer diolah 2017

Strategi WO adalah strategi yang bersifat turn around, memanfaatkan peluang yang ada dengan sebesar-besarnya dengan cara meminimalisir kelemahan. Wanita nelayan memiliki kontribusi yang cukup berarti terhadap kondisi perekonomian rumah tangganya sendiri.

\section{SIMPULAN DAN SARAN}

\section{Simpulan}

1. Bentuk kegiatan yang dilakukan keluarga nelayan selain melaut di Gampong Langkak Kecamatan Kuala Pesisir Kabupaten Nagan Rayaantara lain dengan cara:

a. Bertani, kegiatan tambahan guna untuk memenuhi kebutuhan hidup seharihari,bukan dianggap sebagai usaha dagang.

b. Usaha menjemur udang sabu yang dilakukan oleh istri dan anak nelayan untuk membantu penghasilan suami yang minim.

c. Buruh pabrik, kegiatan keluarga ini untuk dapat menambah penghasilan atau pendapatan dalam keluarga.

2. Strategi pemberdayaan wanita Nelayan dalam peningkatan Ekonomi Keluarga Di Gampong Langkak Kecamatan Kuala Pesisir Kabupaten Nagan Raya dilakukan dengan melakukan program :

a. Program pemberdayaan wanita dalam bidang kelautan untuk meningkatkan produksi kerajinan berbahan dasar udang seperti pelatihan wanita nelayan dalam pembuatan kerupuk udang, abon, dan terasi.

b. Program pemberdayaan wanita nelayan diluar bidang non kelautan seperti Pelatihan Kewirausahaan dan Pelatihan industri rumahan, seperti pelatihan membuat kue basah

\section{Saran}

1. Keluarga Nelayan dapat menerapkan strategi yang didapat dalam penelitian ini untuk meningkatkan ekonomi keluarga.

2. pemerintah sekitar lebih memperhatikan kondisi daerah pesisir, memberi pelatihan membuat produk berbahan dasar hasil laut.

\section{DAFTAR PUSTAKA}

Astuti, W. A. 2013. Peran Ibu Rumah Tangga Dalam Meningkatkan Pendapatan Kesejahteraan Keluarga. Jurusan Pendidikan Luar Sekolah Fakultas Ilmu Pendidikan. Universitas Negeri Malang.

Astrid Ekaningdyah. 2005. Peran Wanita Dalam Peningkatan Pendapatan Keluarga Nelayan Di Desa Tasikagung Kecamatan Rembang Kabupaten Rembang Jawa Tengah. jurusan Perencanaan Wilayah Dan Kota Fakultas Teknik Universitas Diponegoro. Semarang. 
Endang Retnowati. 2011. Nelayan Indonesia Dalam Pusaran Kemiskinan Struktural (perspektif sosial ekonomi dan hukum). XVI. No. 3.

Fatma Zohra. 2008. Strategi Pemberdayaan Ekonomi Sosial Masyarakat Nelayan Berbasis Komunitas Ibu Rumah Tangga Di Desa Pusong Baru Kecamatan Banda Sakti Kota Lhokseumawe. Thesis Sekolah Pasca Sarjana Universitas Sumatera Utara. Medan.

Hany, H. Rahayu, R. Eko, H. 2015. Peran Gender dalam Keluarga Nelayan Tradisional dan Implikasinya pada model Pemberdayaan Perempuan di Kawasan Pesisir Malang Selatan. ISSN 2442-2614. 1 - 21.

Hisyam, M. 2000.Indonesia menapak Abad 21dalam Kajian Sosial dan Budaya. Jakarta, Peradaban.

Horton dan Hurt. 1996. Sosiologi. Jakarta : Erlangga.

Irham Fahmi. 2013. Manajemen Strategis Teori dan Aplikasi. Penerbit Alfabeta.

Iskandar putong. 2003. Teknik Pemanfaatan Analisis SWOT Tanpa Skala Industri (A-SWOT-

TS). Jurnal Ekonomi dan Bisnis. No 2, jilid 8, hlm. 65-71

Jume'edi. 2005. Peran Wanita Dalam Meningkatkan Pendapatan Keluarga Nelayan di

Kelurahan Ujungbatu Kecamatan Jerapan Kabupaten Jerapa. Program Pasca

Sarjana Universitas Panegoro. Semarang.

Kusnadi. 2000. Polemik Kemiskinan Nelayan. Jakarta.Pustaka jogja.

--------, et al. 2006. Perempuan Pesisir. LKIS. Yogyakarta.

Maulana, F. dan Rikri, R. 2015. Peran Istri Nelayan Dalam Meningkatkan Pendapatan Rumah Tangga( Studi Kasus di Desa Penjajab, Kecamatan Pemangkat, Kabupaten Sambas). Sosek KP. Vol : 10 (No.2) 241-249.

Matheus, N. 2005. Pemberdayaan Masyarakat nelayan Di Kabupaten Pasuruan Kajian Pengembangan Model Pemberdayaan Sumberdaya Manusia di Wilayah Pesisir Pantai. jurnal Teknologi Pangan Vol : 6 (No.1).

Nurudinatun, M. S. 2017. Pemberdayaan Perempuan Nelayan Ekonomi Keluarga Perspektif Ekonomi Islam (Studi Terhadap Kelompok Usaha Pengelolaan Mina 7 Desa Tasikmadu Kecamatan Watulimo Kabupaten Trenggalek). Jurusan Ekonomi Syariah Fakultas Ekonomi dan Bisnis Islam Institut Agama Islam Negeri. Tulungagung.

Nadia, W. Christian, D. Dan Olvie, K. 2013. Karakteristik Sosial Ekonomi Masyarakat Nelayan Di Desa Lopana Kecamatan Amurang Timur Propinsi Sulawesi Utara. Jurnal Ilmiah, PS. Agribisnis Perikanan UNSRAT, Manado. ISSN 2337-4195 Vol. 1 No.2.

Rangkuti, F. 2010. Analisis SWOT :Teknik Membedah Kasus Bisnis. Penerbit PT Gramedia Pustaka Utama. Jakarta.

Sunadji, R. Tobuku, dan Y. Jasmanindar. 2005. Peran Serta Wanita Nelayan Dalam Pendapatan Keluarga. Laporan Penelitian. Direktorat Jenderal Pendidikan

Strategi pemberdayaan Wanita Nelayan Dalam Peningkatan Ekonomi Keluarga di Gampong Langkak 
Tinggi. Departemen pendidikan Nasional. Fakultas Pertanian Universitas Padjajaran. Bandung.

Sebenan, R. D. 2007, Strategi Pemberdayaan Rumahtangga Nelayan di Desa Gangga II Kecamatan Likupang Barat Kabupaten Minahasa Utara. Fakultas Perikanan dan Ilmu Kelautan, Universitas Sam Ratulangi, Manado.

Siti Amanah. 2010. Peran Komunikasi Pembangunan dalam pemberdayaan Masyarakat. Jurnal Komunikasi Pembangunan. ISSN 1693-3699 Vol: 08 ( No. 1).

Tri Joko Sri Haryono. 2005. Strategi Kelangsungan Hidup Nelayan (studi tentang diversifikasi Pekerjaan keluarga nelayan sebagai salah satu strategi dalam mempertahankan kelangsungan hidup). Vol :7( No.2).

Trie, U. A. Iwang, G. Dan Roffi, G. 2012. Kontribusi Ekonomi Produktif Wanita Nelayan Di Pangandaran Kabupaten Ciamis. ISSN 2088-3137 Vol: 3 ( No.3).

Wahyu Fitriyanti. 2016. Analisis Pendapatan dan Strategi pemberdayaan Istri Nelayan Dalam Upaya Meningkatkan Pendapatan Rumah Tangga (Studi Empiris : Kecamatan Pekalongan Utara, Kota Pekalongan). Fakultas Ekonomika dan Bisnis Universitas Diponegoro, Semarang.

Yulianah. 2016. Pemberdayaan Keluarga Nelayan Melalui Program Usaha Bersama (KUBE) Di Kampung Maccini Baji Kelurahan Pundata Baji Kecamatan Labakkang Kabupaten Pangkep. Fakultas Dakwah Dan Komunikasi. PMI/Kesejahteraan Sosial. Universitas Islam Negri. Al-Auddin Makassar. 